\title{
Inertial-Dissipation flux measurements over south Bay of Bengal during BOBMEX-Pilot experiment
}

\author{
M Venkataramana ${ }^{1}$, K Sengupta ${ }^{1}, \mathrm{G} \mathrm{S} \mathrm{Bhat}^{2}$, $\mathrm{S} \mathrm{Ameenulla}^{2}$ and J V S Raju ${ }^{2}$ \\ ${ }^{1}$ Space Physics Laboratory, Vikram Sarabhai Space Centre, Trivandrum 695 022, India \\ ${ }^{2}$ Centre for Atmospheric and Oceanic Sciences, Indian Institute of Science, Bangalore 560 012, India
}

\begin{abstract}
This paper describes measurement of air-sea parameters and estimation of sensible and latent heat fluxes by the "Inertial-Dissipation" technique over south Bay of Bengal. The data were collected on ORV Sagar Kanya during BOBMEX-Pilot cruise during the period 23rd October 1998 to 12th November 1998 over south Bay of Bengal. The fluxes are estimated using the data collected through fast response sensors namely Gill anemometer, Sonic anemometer and IR Hygrometer. In this paper the analyses carried out for two days, one relatively cloud free day on November 3rd and the other cloudy with rain on November 1st, are presented. Sea surface and air temperatures are higher on November 3rd than on November 1st. Sensible heat flux for both the days does not show any significant variation over the period of estimation, whereas latent heat flux is more for November 3rd than November 1st. An attempt is made to explain the variation of latent heat flux with a parameter called thermal stability on the vapor transfer from the water surface, which depends on wind speed and air to sea surface temperature difference.
\end{abstract}

\section{Introduction}

The turbulent heat fluxes (sensible and latent) are important components of the total heat budget at the air-sea interface. The momentum flux (surface stress) is the major driver of ocean turbulence and surface currents. The surface sensible and latent heat fluxes represent interfacial inputs of heat and moisture into the boundary layer that influence convection, the formation of clouds and precipitation. There are four standard techniques for calculating these fluxes from atmospheric measurements:

- covariance (eddy correlation),

- inertial subrange dissipation and direct dissipation,

- profiles

- bulk aerodynamical methods.

By definition the fluxes are the ensemble Reynolds averages of the instantaneous vertical air velocity component with horizontal velocity, enthalpy and water vapour density to give the stress, sensible heat flux and latent heat flux respectively. The covariance method is a direct computation from the data and yields a flux which is considered an unbiased estimate of the intrinsic flux at the height of the measurement, but subject to sampling uncertainty i.e., it requires measurements of the vertical and downwind component of air velocity, temperature and humidity over a sufficiently long averaging period and with sufficient frequency response (Wyngaard 1973). The covariance method is used extensively over land, but straightforward application over the ocean is limited to fixed towers. If one wishes to apply this method on a moving platform (ship or aircraft), then the orientation and motion of the platform must be accounted for before computing the correlations. Furthermore, distortion of the flow by the ship superstructure may invalidate the results. The profile method requires precise measurements of the vertical gradient of the mean meteorological variables, which has proven to be a very difficult task from a ship (Blanc 1983). The bulk method requires only mean meteorological information and is the obvious choice for climatological studies and numerical models. The bulk

Keywords. Planetary boundary layer; air-sea flux; turbulence. 
aerodynamic method (drag coefficients) has and will continue to have a special place in flux estimation method, simply because of its extensive use in numerical models and its applicability to historical data sets from weather ships, buoys and ships of opportunity. For bulk meteorological data of reasonable quality the major source of uncertainty in the long-term mean estimates of stress, sensible heat and latent heat is probably due to uncertainties in the airsea transfer coefficients. The dissipation method, which relies on measurements at high frequencies is unaffected by ship motion. This method is a good compromise, being insensitive to platform motion (unlike covariance method) and relatively insensitive to platform distortion of the airflow (unlike the covariance and profile methods). The dissipation methods (high frequency turbulence), is more direct than the bulk method simply because it is true turbulence statistics. The dissipation method is also advantageous if the sensors are not situated close enough to each other to correctly measure crosscorrelations. Studies using the dissipation methods over the ocean (Pond et al 1971, Scharcter et al 1981) and over land (Champagne et al 1977, Mestayer et al 1980) have yielded good results.

\subsection{Scope of this paper}

This paper describes the air-sea fluxes using the inertial-dissipation method during BOBMEX-Pilot experiment. The paper is divided into five sections. The instrumentation and data acquisition are described in section 2 . In section 3 , the theory, methodology and corresponding formula of turbulent flux measurements using Inertial-Dissipation method are described. Weather conditions and results are discussed in section 4. Our conclusions are given in section 5 .

\section{Instrumentation and data acquisition}

The pilot experiment was carried out on board ORV Sagar Kanya. The ship left Mormugao on 23rd October 1998 and reached the first stationary time series station located at $7^{\circ} \mathrm{N} 87^{\circ} \mathrm{E}$ on October 30th where it halted for two days. The second time series station was at $10^{\circ} \mathrm{N} 87^{\circ} \mathrm{E}$ for two days (2nd-3rd November), and the last time series station for a day was located at $13^{\circ} \mathrm{N} 87^{\circ} \mathrm{E}$ on November 5th. The ship started sailing back on November 6th and reached Tuticorin on November 12th, 1998. The instrumentation system on board ORV Sagar Kanya Cruise \#138C for the estimation of air-sea fluxes consisted of sonic anemometer for measuring the 3-dimensional wind vector and the virtual temperature, IR-hygrometer for the specific humidity, accelerometers for the determination of the ship motion, Gill $u, v, w$ sensors for measuring triaxial wind vector. The above sensors were having a frequency response of $10 \mathrm{~Hz}$ or more. For mean parameters there were slow response sensors (frequency response less than $1 \mathrm{~Hz}$ ) which included Humicap for measuring relative humidity, platinum resistance thermometer for air temperature, pyranometers for measuring short wave and long wave radiation and rain gauge for measuring the rainfall were used. Specifications of the instruments used and the schematic of the sensors deployed at different levels over the boom are explained in Bhat et al (this issue). A pentium PC working on Windows-95 was used for acquiring and storing the data. Data acquisition and archival were controlled by DASYLab software. Apart from acquiring the date, DASYLab was programmed to display all the parameters on the screen in real time for visual monitoring. The signals from the sensors were sampled at $10 \mathrm{~Hz}$. The data from the fast sensors were stored at $10 \mathrm{~Hz}$ rate, for a one-hour period every three hours. In addition, data from all the sensors were averaged for 10 seconds and continuously stored.

During the campaign, high-resolution radiosondes manufactured by M/s. Atmospheric Instrumentation Research (AIR) Inc., USA were launched using 300-g balloons. These provided the vertical profiles of temperature and humidity fields of the atmosphere as a function of pressure at 5-second interval. The temperature, humidity and pressure data transmitted by the radiosonde were received through antenna, and the RS232 output from the receiver was sent to a note-book PC for data display and archival. GPS data were also collected by installing a GPS system on board Sagar Kanya.

There were also independent surface meteorological measurements from the ship including ship position (latitude, longitude and heading with respect to north) barometric pressure, dry bulb and wet bulb temperatures, and sea surface temperatures every three hours manually. The sea surface skin temperature was measured by an infrared thermometer. The infrared thermometer was not used during rains.

\section{Flux determination by the inertial- dissipation method}

There are many different scales of motion in meteorology. They extend from the trade winds that exist over the equatorial oceans to the Kolmogorov inertial subrange, and molecular viscosity. Since spectral analysis of meteorological variables is essentially a statistical method of describing fluctuations, it enables us to study the various aspects of boundary layer structure like the predominant scales of motion, the nature of energy containing eddies, the nature of cascading in the inertial-subrange, the intermittent outbreak of 
turbulence induced by terrain and mesoscale process, modifications by plume and wave activity and the estimation of the size of eddies that carry maximum energy (Winston et al 1993).

The dissipation technique is based on Kolmogorov's theoretical prediction of universality in the inertial subrange. Spectra are measured in the inertial regime, related to the turbulent kinetic energy (TKE) dissipation rate via Kolmogorov's equation. The main attraction of dissipation methods is their use of MoninObukhov similarity forms for the high-frequency portion of the spectrum, where platform motions are negligible in relation to turbulence signals. There is a distinction between "direct" measurements of dissipation rates by integrating over the spectrum of the derivative versus the "inertial-dissipation" method, using a fit to the Kolmogorov $f^{-5 / 3}$ power law in the inertial subrange to determine the appropriate structure function parameter (Fairall et al 1990). "Direct" dissipation methods are rarely made over the ocean because fast response sensors that can measure temperature and humidity fluctuations of the order of $5 \mathrm{kHz}$ are difficult to maintain in the marine environment. Henceforth we refer to the "inertial-dissipation" method, which requires frequency response only up to the order of $5-50 \mathrm{~Hz}$. It is based on the assumption that turbulent fluxes of momentum, sensible heat and water vapour are linked to the spectra of velocity $\left(S_{u}(f)\right)$, temperature $\left(S_{t}(f)\right)$ and absolute humidity $\left(S_{q}(f)\right)$ variances through the dissipation of turbulent kinetic energy, temperature and humidity variances (Fairall and Larsen 1986). The spectra of wind, temperature and absolute humidity follow a power law $\left[S_{u}(f), S_{t}(f)\right.$ and $\left.S_{q}(f) \propto f^{-5 / 3}\right]$ over an inertial subrange of frequencies. Fluxes can be estimated from measurements of spectra within this subrange, which is typically found to apply at normalized frequencies $f_{n}=f z / u \geq 1$ (Phelps and Pond 1971).

The surface latent heat fluxes can be calculated from the expressions of the form (Smith 1989)

$$
\begin{aligned}
\langle w q\rangle_{\text {Diss }}= & S_{E}[2 \pi k z / U]^{2 / 3} f^{5 / 3} \\
& \times\left[S_{u}(f) \cdot S_{q}(f) /\left(k^{\prime} \cdot \beta_{q}\right)\right]^{1 / 2} .
\end{aligned}
$$

Where $S_{E}$ is stability dependence coefficient and is given by

$$
S_{E}=\left[\Phi_{q}(Z / L)\right]^{-1 / 2}\left[\Phi_{m}(Z / L)-Z / L\right]^{-1 / 6} .
$$

Where the one-dimensional Kolmogorov constants are $k^{\prime}=0.55$ for velocity and $\beta_{q}^{\prime}=0.80$ for humidity (Paquin and Pond 1971). $U$ is mean wind, $z$ is the height of observations and $k$ is Von Karman constant.

Review of the flux-profile relationships (Dyer 1974, Yaglom 1977) indicates the reasonable forms as

If $0<Z / L<0.2$

$$
\begin{aligned}
\Phi_{m}(Z / L) & =1+7 Z / L \\
\Phi_{t}(Z / L)=\Phi_{q}(Z / L) & =1+7 Z / L
\end{aligned}
$$

$$
\begin{aligned}
& \text { If }-1.0<Z / L<0 \\
& \Phi_{m}(Z / L)=(1-16 Z / L)^{-1 / 4} \\
& \Phi_{t}(Z / L)=\Phi_{q}(Z / L)=(1-16 Z / L)^{-1 / 2} \text {. }
\end{aligned}
$$

Where $L$ is the Monin-Obukhov length with both humidity and temperature effects included and $Z / L$ is given by (Deardroff 1968)

$$
\begin{aligned}
\frac{Z}{L}= & \frac{-100 z}{(U z)^{2} T_{0}} \\
& \times\left[\Delta \theta+1.7 \times 10^{-6} T_{0}^{2} \Delta q\right] \Delta \theta>0 \text { unstable } \quad(5) \\
= & \frac{70 z}{(U z)^{2} T_{0}}\left[\Delta \theta+2.5 \times 10^{-6} T_{0}^{2} \Delta q\right] \Delta \theta<0 \text { stable. }
\end{aligned}
$$

Where $T_{0}$ is mean temperature of the layer, $\Delta \theta$ is difference between sea surface temperature and air temperature at $10 \mathrm{~m}$ and $\Delta q$ is difference between absolute humidity at the sea surface and $10 \mathrm{~m}$ level.

The advantage of the inertial-dissipation method over the eddy correlation method is that the vertical component of the wind is not required, and so constraints on the rigidity and flow-distortion of the supporting structure can be relaxed. Sensible heat flux $\langle w t\rangle_{\text {Diss }}$ calculation is analogues to that of $\langle w q\rangle_{\text {Diss }}$.

\section{Results}

First, let us consider the synoptic conditions during the BOBMEX-Pilot period. Kalsi (1999) reported that the conditions prevailing during the pilot experiment were typical of the cyclone period in this part of the globe. He reported that a weak disturbance on 26th October 1998 was seen to migrate from the Gulf of Thailand westwards across the Andamans into the central part of the Bay of Bengal and became unimportant on 31st October. INSAT-ID satellite visible imagery showed that new cloud bands formed between $65^{\circ} \mathrm{E}$ and $90^{\circ} \mathrm{E}$ around $3^{\circ} \mathrm{N}$ on October 31st, moved northward and passed over ORV Sagar Kanya on November 1st. The system intensified into a tropical storm as it approached Tamilnadu coast on November 3rd, and the entire south of India experienced heavy rains for the next couple of days. As observed from the ship during the period between October 30th - November 2nd the sky was mostly covered with cumulus clouds. As preliminary analyses we have chosen two typical days, one relatively cloud free day (November 3rd) and the other being cloudy with rain or continuous drizzle (November 1st).

The daily mean surface pressure decreased from around $1009 \mathrm{mb}$ on October 28th to around $1006 \mathrm{mb}$ on November 5th and then gradually increased. On November 1st thick deep clouds were seen from the ship and $20 \mathrm{~mm}$ rain was recorded on board the ship. It was observed that wind speed varied from less than a meter per second to more than $10 \mathrm{~ms}^{-1}$. Winds were 

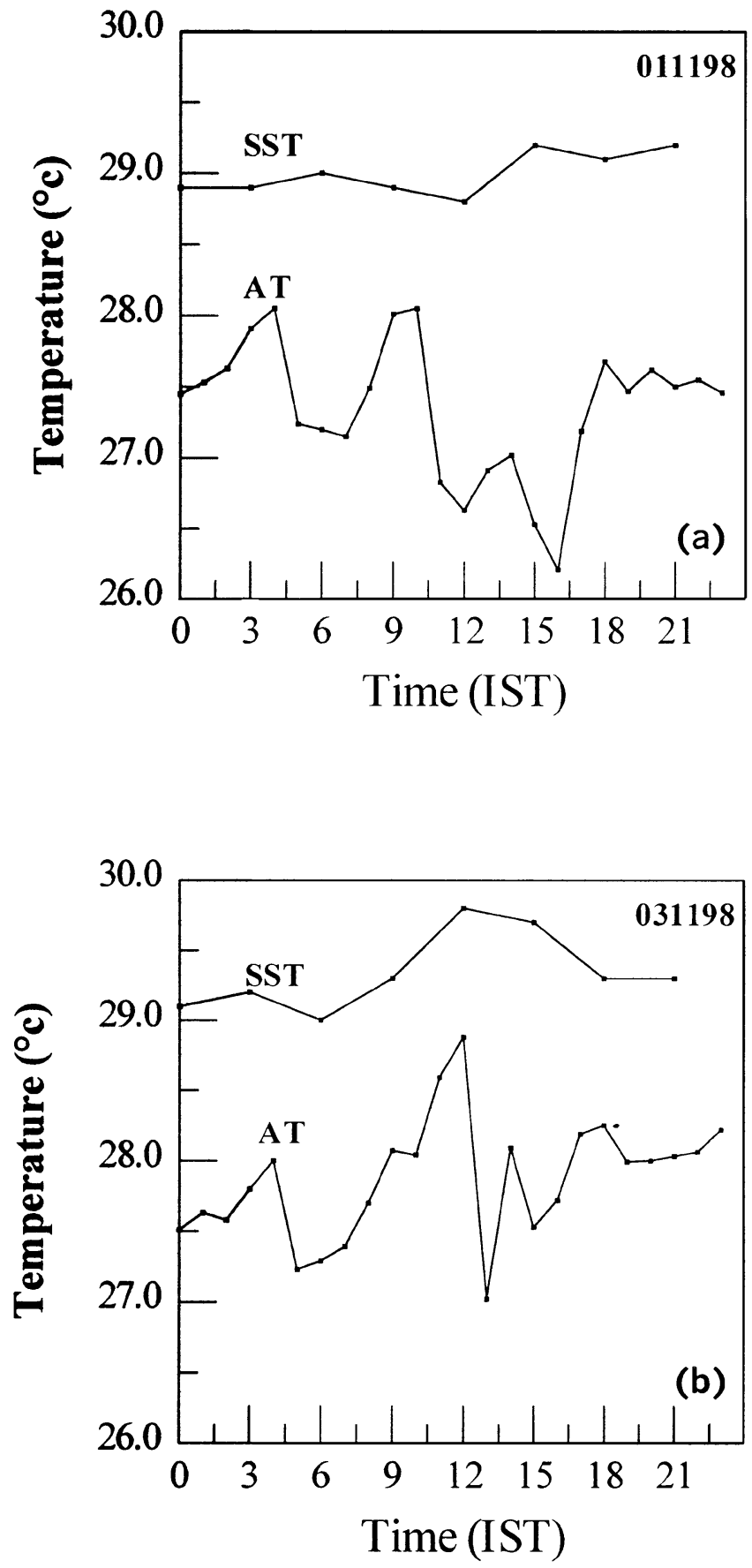

Figure 1. Three hourly values of sea surface temperature (SST) and hourly values of air temperature (AT) at $11 \mathrm{~m}$ above the sea surface for (a) November 1st 1998 and (b) November 3rd 1998.

mostly westerlies and south westerlies till November 4 th and then became north easterlies. On some occasions, wind speeds larger than $13 \mathrm{~ms}^{-1}$ have been observed for short time durations associated with systems. Sea surface temperature was warmer than $28^{\circ} \mathrm{C}$ with an average near $29^{\circ} \mathrm{C}$; and maximum sea surface temperature $29.8^{\circ} \mathrm{C}$ was observed on November 3rd. The relative humidity was $80 \%$ and for most of the time with an average around $83 \%$ i.e., the air was very rich in moisture.
Figures 1(a) and 1(b) show three hourly values of sea surface temperature (SST) and hourly values of air temperature (AT) at $11 \mathrm{~m}$ above the sea surface for November 1st and 3rd respectively. For both the days SST was higher than AT indicating unstable condition, in general. SST on November 3rd shows more diurnal variation than November 1st, as the 1st was generally cloudy. On an average the difference between SST and AT was more on November 3rd than on the 1st. As November 1st was associated with
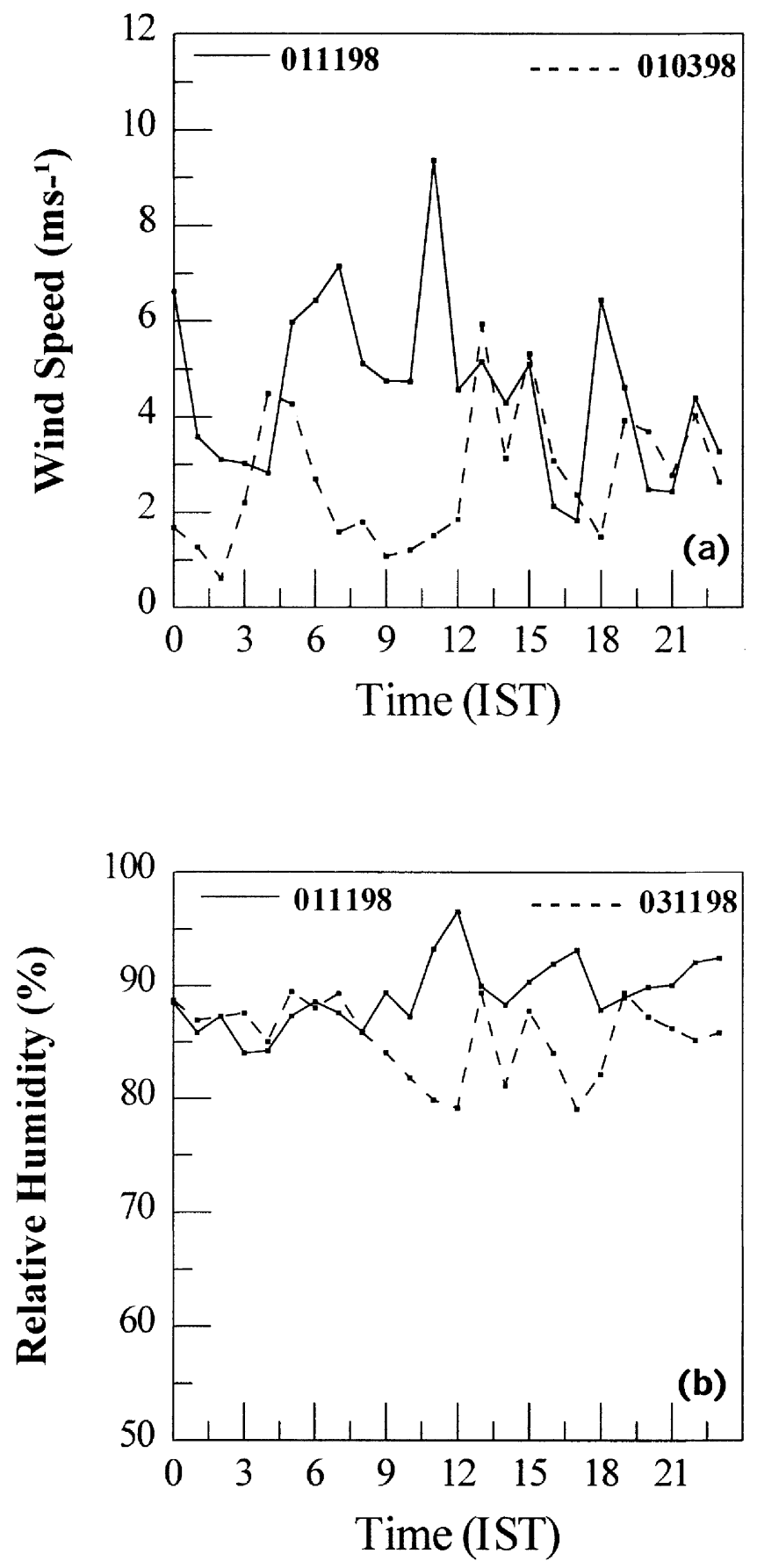

Figure 2. (a) Corrected horizontal wind speed measured by the sonic anemometer. (b) Relative humidity. Data shown are hourly averages. 
the system, we observed higher wind speeds on the 1st than on the 3rd as shown in figure 2(a). Figure 2(b) shows hourly values of relative humidity $(\mathrm{RH})$ for November 1st (continuous line) and November 3rd (dashed line) at $11 \mathrm{~m}$ height above the sea surface. It shows the gradient of RH between the sea surface and $11 \mathrm{~m}$ was more on November 3rd than on the 1st. Figure 3(a) shows incoming solar radiation measured by the pyranometer on November 1st and 3rd. It is seen from figure $3(\mathrm{a})$ that deep clouds drastically reduced the solar insolation reaching the surface on
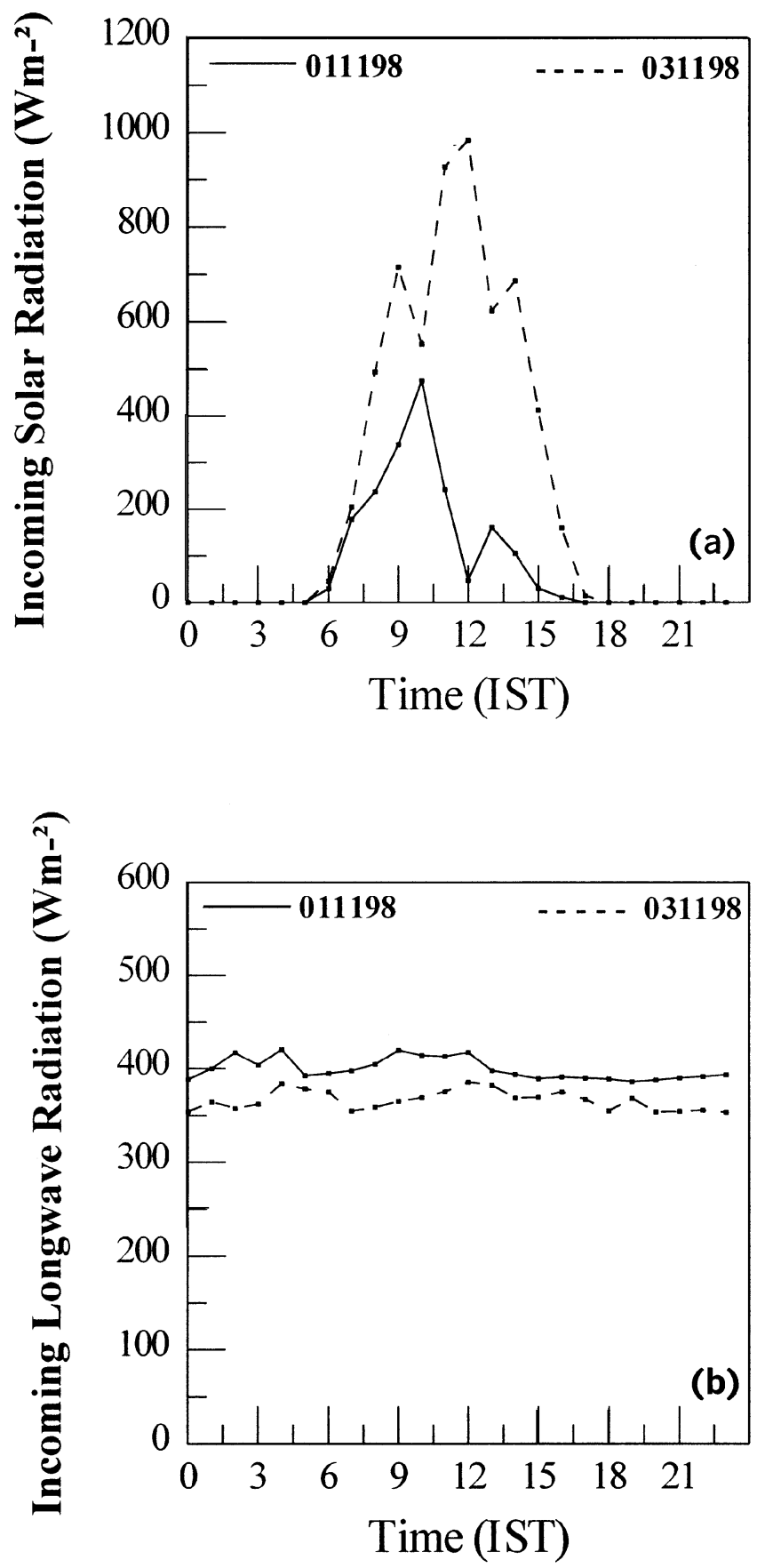

Figure 3. Incoming solar radiation (a) and incoming longwave radiation (b) for November 1st and November 3rd, 1998.
November 1st except for some time between 9 am and $10 \mathrm{am}$. On November 3rd, the morning was sunny and the peak short wave radiation reached $984 \mathrm{~W} \cdot \mathrm{m}^{-2}$ around noon. The hemispheric incoming longwave radiation (ILR) measured by the upward facing infrared pyranometer is shown in figure $3(\mathrm{~b})$. Comparison of IR pyranometer data of November 1st and 3rd shows that ILR flux is enhanced by $25-60 \mathrm{~W} . \mathrm{m}^{-2}$ in the presence of deep clouds, indeed, $20 \mathrm{~mm}$ of precipitation was observed on the 1st.

For the computation of sensible heat flux (SHF) and latent heat flux (LHF), one hour data length with $1 \mathrm{~Hz}$ sampling rate, amounting to 3600 data points have been subject to a mixed radix Fast Fourier Transform and the spectrum is then smoothed by averaging the spectral information over frequency bands of increasing width. Figures 4 and 5 show sample power spectra of u-component of wind, absolute humidity $(q)$ and sonic temperature $\left(T_{s}\right)$ obtained for November 1st and 3rd respectively, during $1500 \mathrm{hrs}$, measured at a height of $11 \mathrm{~m}$ above the sea surface. The spectra showed the typical dropoff of energy with increasing frequency that is normally found for meteorological parameters over the frequency band examined. The general characteristic of the unstable spectrum with a ' $-5 / 3$ ' slope in the inertial-subrange is evident in all the spectra. In figure 5 the power spectral density is high due to high turbulence activity for the convective atmospheric boundary layer on November 3rd. Figure 4 shows the existence of the spectral gap (as marked in the figure) in the gravity wave frequency range of power spectra for November 1st. The classical study of Van Der Hovan (1957) extends over at least seven decades on the frequency scale and represents a variety of flow regimes, governed by widely different mechanisms. The two spectral peaks in Van Der Hovan's spectrum represent the two dominating types of flow: the quasi horizontal motion with their center of gravity in the range $10^{-6}-10^{-5} \mathrm{~Hz}$, and the genuine turbulence, the maximal energy of which is located roughly at $10^{-2} \mathrm{~Hz}$ if the measurements are taken at standard anemometer level. In the intermediate spectral region several special "mesoscale" types of flow are known to exist, such as deep convection, large roll vortices, and local circulations (land and sea breeze). As pointed out by Hess and Clarke (1973) the existence of a gap depends on both the strength of the microscale turbulence and the spectral shape in the synoptic-mesoscale region. Kolesnikova and Monin (1965) also try to relate the value of the gap to synoptic situations, but they can only draw the conclusion that these spectral divisions vary with weather conditions. The small peaks in figures 4 and 5 at the frequency of around $0.1-0.2 \mathrm{~Hz}$ in the $u$ spectrum are due to contamination by the ship motion (Fujitani 1985). The scalar variables are much less affected. 

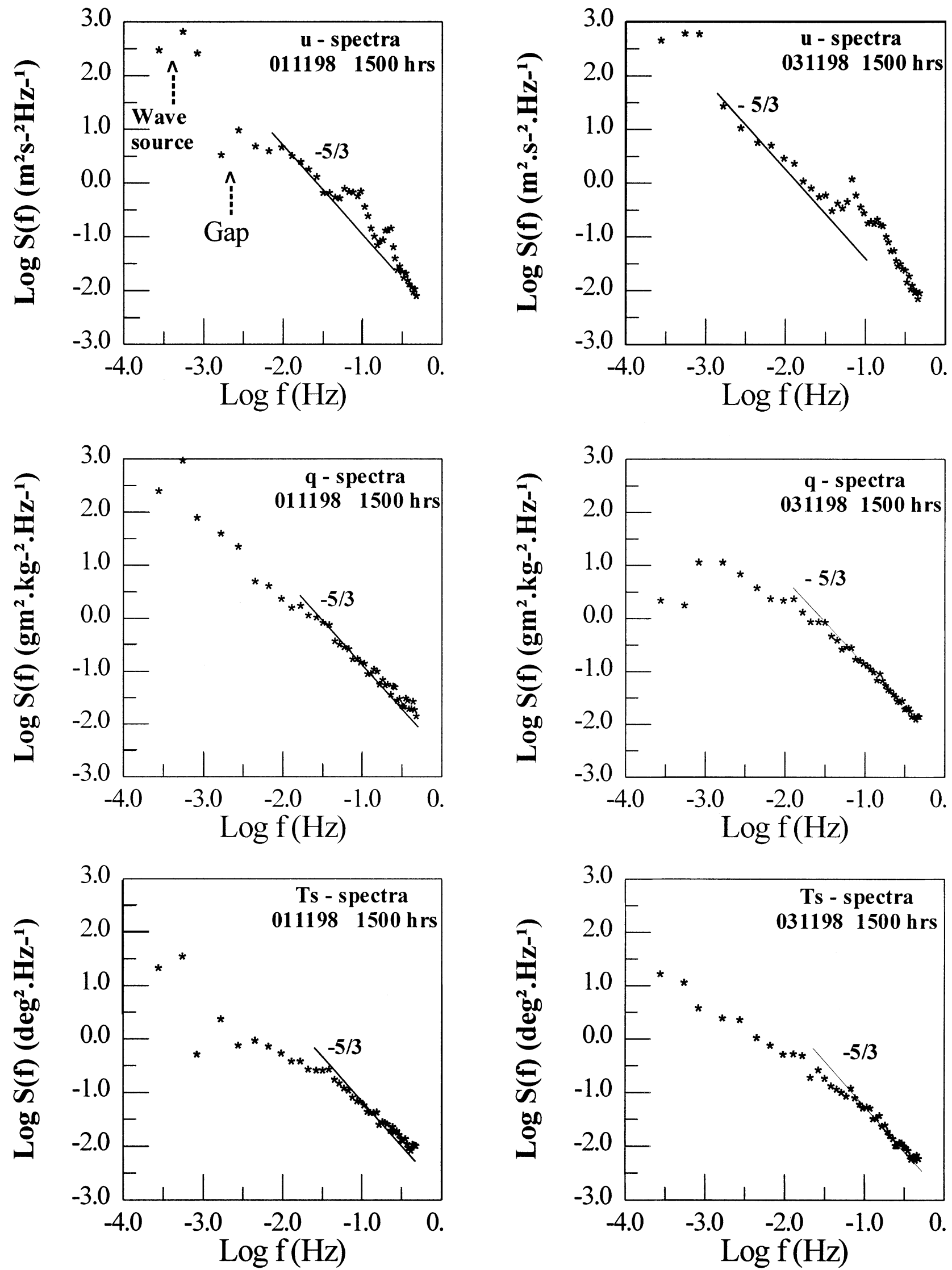

Figure 4. Power spectra of $u$-component of wind, absolute humidity $(q)$ and sonic temperature $\left(T_{s}\right)$ with frequency for November 1st, 1998 during 1500 hrs. The thick line with $-5 / 3$ slope indicates inertial sub-range.

Figure 5. Power spectra of $u$-component of wind, absolute humidity $(q)$ and sonic temperature $\left(T_{s}\right)$ with frequency for November 3rd, 1998 during 1500 hrs. The thick line with $-5 / 3$ slope indicates inertial sub-range. 

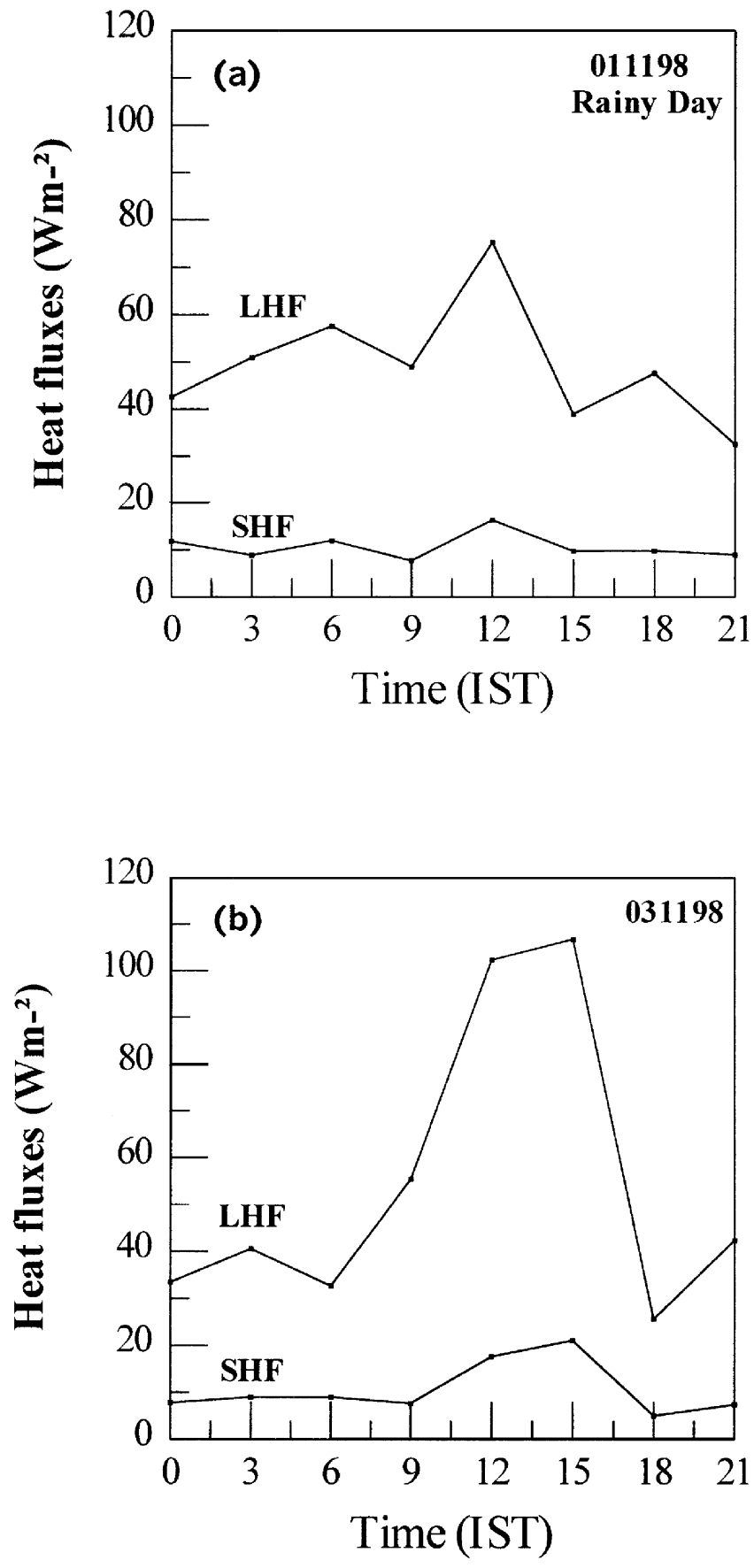

Figure 6. Turbulent fluxes of latent heat (LHF) and sensible heat (SHF) estimated using Inertial-Dissipation method for (a) November 1st, 1998 and (b) November 3rd, 1998.

Fluxes are estimated using the inertial dissipation method as described in section 3 . The spectral power of velocity $\left(S_{u}(f)\right)$, absolute humidity $\left(S_{q}(f)\right)$ and temperature $\left(S_{t}(f)\right)$ were obtained at non-dimensional frequency $f$; satisfying the condition $f z / U \geq 1$. To obtain the spectral power at $f$ satisfying the condition $f z / U \geq 1$ often the spectral slope of $-5 / 3$ in the inertial-subrange has been extended and interpolated values of spectral power densities have been taken and used in equation (1). Hence, contamination of spectra, if any, by the ship motion; will not affect the flux estimation by this method. Fluxes thus obtained are shown in figures $6(\mathrm{a})$ and $6(\mathrm{~b})$ for the two days. The SHF is a very small part of the total heat flux and does not seem to vary much for both the days November 1st and 3rd. LHF is more for November 3rd than for the 1st because of more of $\mathrm{RH}$ gradient being observed on the 3rd. To examine the variation of LHF, we considered the effect of the thermal stability on the vapor transfer from the water surface. Assouline and Mahrer (1993) concluded that temperature and wind speed are two main factors affecting LHF from the open water surface.

The combined effect of the temperature and wind speed can be examined in terms of stability parameter, $S_{R}$ (analogous to the Richardson number)

$$
S_{R}=(g / T)(\mathrm{AT}-\mathrm{SST})\left(z / U^{2}\right)
$$

where $g$ is acceleration due to gravity, AT is the air temperature at a height $(z)$ of $11 \mathrm{~m}, \mathrm{SST}$ is the sea surface temperature, $T$ (in $\mathrm{K}$ ) is the mean temperature of the layer $(T=(\mathrm{AT}+\mathrm{SST}) / 2)$, and $U$ is the wind speed at a height of $11 \mathrm{~m}$. The diurnal variations of stability parameter $\left(S_{R}\right)$ for the two days are shown in figure 7. A sharp decrease in the magnitude of LHF between 1500 and $1800 \mathrm{hrs}$ is related to value of $S_{R}$ $(-0.02)$ close to neutral, as shown in figure 7 . Bowen's ratio was found to vary from 0.1 to 0.2 , which is typical over tropical oceans. Figure 8 shows the RH profiles on October 25th (over the Arabian Sea) and on November 1st and 3rd (over Bay of Bengal). Profiles over the Bay of Bengal showed constant RH up to $500 \mathrm{mb}$ whereas the profile over the Arabian Sea showed a marked decrease in $\mathrm{RH}$ above the boundary layer. The general decrease in $\mathrm{RH}$ above the mixed

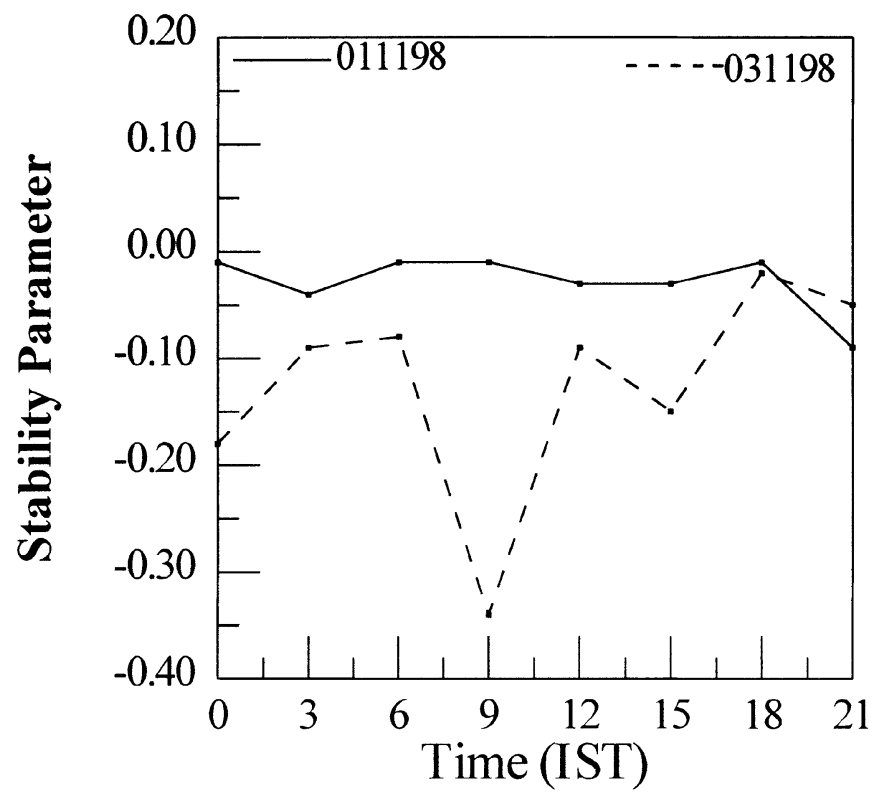

Figure 7. Stability parameter $\left(S_{R}\right)$ measured for (a) November 1st, 1998 and (b) November 3rd, 1998. 


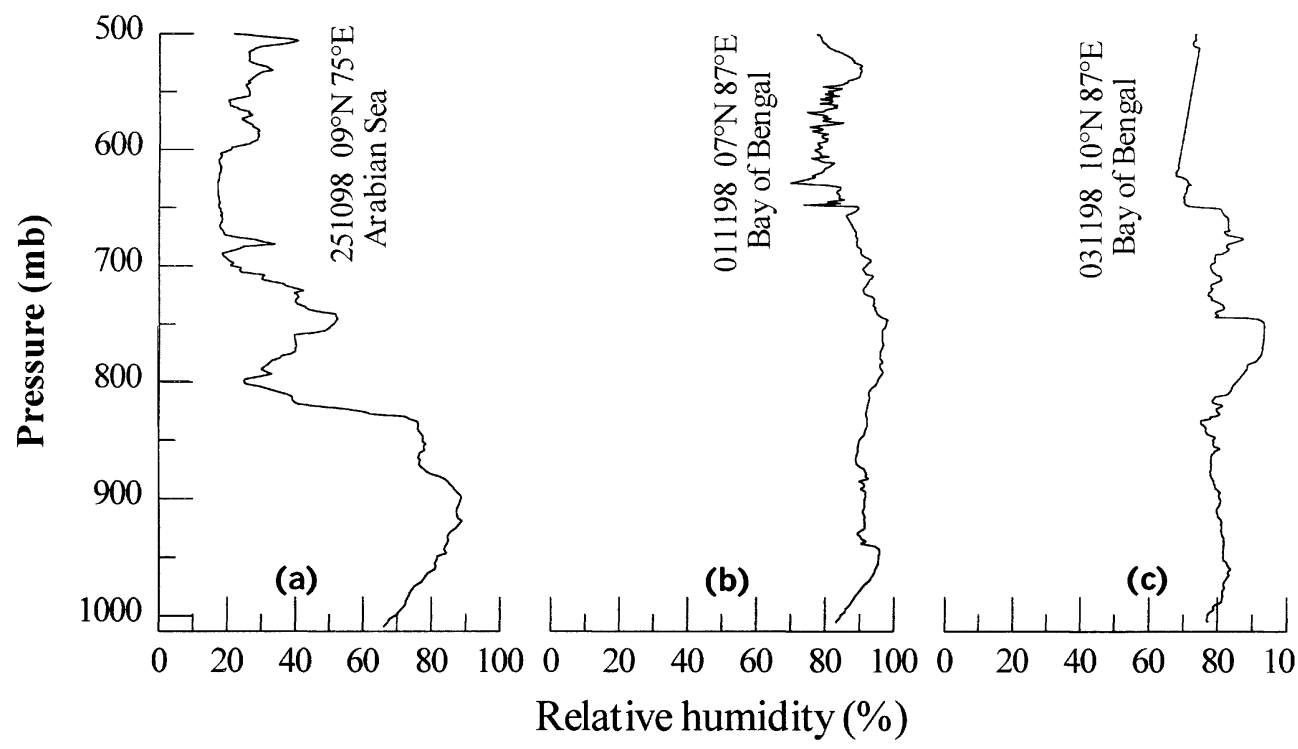

Figure 8. Relative humidity as function of the pressure height for (a) October 25th, 1998 over the Arabian Sea and (b) November 1st, 1998 (c) November 3rd, 1998 over the Bay of Bengal during 1400 hrs.

layer inversion is absent in the profile over the Bay of Bengal, which could be due to the presence of high level clouds and cumulonimbus clouds over the Bay of Bengal. However, in a companion paper, Bhat et al (in this issue) present an overview of the variation of the mixed layer height over the Bay of Bengal. They found that the height of the mixed layer varied from $500 \mathrm{~m}$ to $900 \mathrm{~m}$ with a mean between 400 and $600 \mathrm{~m}$.

\section{Conclusions}

A sea going system capable of complete surface flux and sophisticated boundary layer profile measurement has been demonstrated through this BOBMEX-Pilot trail cruise. Comprehensive, synergistic and highquality data over the Bay of Bengal have never been available before and are potentially quite useful for analysts and modellers. This field program achieved a high level of success.

Mesoscale atmospheric activity over the ocean appeared to exist during a particular period during the pilot experiment of the Bay of Bengal monsoon experiment in 1998. The existence of a spectral gap is important in the discussion of atmospheric motions because these motions can usually be divided into two categories, synoptic and micro-scale, by the spectral gap. Therefore, in general numerical models, the grid size is chosen in the dimension corresponding to the scale of the spectral gap to filter out turbulent noise. However, if there exist significant mesoscale atmospheric motions, large errors in numerical prediction over a long period will be induced from aliasing.

It has been demonstrated that the turbulent heat fluxes, like SHF and LHF can be estimated, by the inertial-dissipation technique, which relies on measure- ments at high frequencies unaffected by ship motion. The most attractive feature of the inertial-dissipation technique is that it avoids an explicit measurement of the vertical velocity.

\section{Acknowledgements}

The authors are thankful to the Department of Science and Technology, Government of India for funding the project. They also thank the I.I.Sc. and SPL divisional members who worked for the project in various stages. Mr. Chandrasekhar, Mr. G Ravi, Mr. Retish Senan of IISc and Mr. Saji Varghese of JNCASR have worked day and night to collect the data on board the ship and we thank them for their excellent job. We also thank Mr. D R Sikka for his valuable comments during the presentation of this paper at the BOBMEX Workshop. Critical reviews by Prof. Sulochana Gadgil helped improve the manuscript. We are particularly grateful for the support extended by the chief scientist Mr. Ramesh Babu of ORV Sagar Kanya.

\section{References}

Assouline S and Mahrer Y 1993 Evaporation from Lake Kinneret', Eddy correlation system measurements and energy budget estimates; Water Resour. Res. 29 901-910

Bhat G S, Ameenulla S, Venkataramana M and Sengupta K 2000 Atmospheric boundary layer characteristics during BOBMEX-Pilot experiment (in this issue)

Blanc T V 1983 An error analyses of profile, flux, stability and roughness length measurements made in the marine atmospheric surface layer; Boundary-Layer Meteorol., 26 234-267

Champagne F H, Friehe C A, La Rue J C and Wyngaard J C 1977 Flux estimation techniques and fine-scale turbulence 
measurements in the unstable surface layer over land; $J$. Atmos. Sci. 34 515-530

Deardroff J W 1968 Dependence of air-sea transfer coefficients on bulk stability; J. Geophys. Res. 73 2549-2557

Dyer, A J 1974 A review of flux-profile relationships; Boundary-Layer Meteorol. 7 363-372

Fairall C W, Edson J B, Larsen S E and Mestayer P G 1990 Inertial-Dissipation air-sea flux measurements: A prototype system using real-time spectral computations; J. Atmos. Oceanic Technol. 7 425-453

Fujitani T 1985 Method of turbulent flux measurement on a ship by using a stable platform system; J. Meteorol. Soc. Japan. 63 157-170

Hess G D and Clarke R H 1973 Time spectra and Cross-spectra of kinetic energy in the planetary boundary layer; Q. J. R. Meteorol. Soc. 99 130-153

Kalsi S R 1999 Synoptic weather conditions during the pilot study of Bay of Bengal and Monsoon Experiment (BOBMEX), Workshop on BOBMEX-Pilot Study Results, held at I.I.T. Delhi, pp 1-2

Kolesnikova V N and Monin A S 1965 Spectra of meteorological field fluctuations; Izv. Atmos. Oceanic Phys. 1 377-386

Mestayer P G, Pages J P, Coantic M and Saissac J 1980 Joint Symposium Heat and Mass Transfer and the Structure of Turbulence, Z. Zaric (ed.) (Washington, DC: Hemisphere publ)

Paquin J E and Pond S 1971 The determination of the Kolomogroff constants for velocity, temperature and mois- ture from second and third order structure functions; $J$. Fluid Mech. 50, part 2, 257-269

Phelps G T and Pond S 1971 Spectra of the temperature and humidity fluctuations and of the fluxes of moisture and sensible heat in the marine boundary layer; J. Atmos. Sci. 28 918-928

Pond S, Phelps G T, Paquin J E, McBean G A and Stewart R W 1971 Measurements of turbulent fluxes of momentum, moisture and sensible heat over the ocean; J. Atmos. Sci. 28 901-917

Scharcter G E, Davidson K L, Houlihen T and Fairall C W 1981 Measurement of the rate of the dissipation of turbulent kinetic energy, $\varepsilon$ over the ocean; Boundary-Layer Meteorol. 20 321-330

Smith S D 1989 Water vapor flux at the sea surface; BoundaryLayer Meteorol. 47 277-293

Van Der Hovan 1957 Power spectrum of horizontal wind speed in the frequency range from 0.0007 to 900 cycles per hour; $J$. Meteorol. 14 160-164

Winston J P, Radhika R, Nair K N, Sengupta K and Kunhikrishnan P K 1993 On the spectral behaviour of atmospheric boundary-layer parameters at Thumba, India Q. J. Meteorol. Soc. 119 187-197

Wyngaard J C 1973 On surface-layer turbulence, in Workshop on micrometeorology, (ed) D. Haugen (American Meteorological Society: Science press) pp 101-149

Yaglom A M 1977 Comments on wind and temperature flux profile relationships; Boundary-Layer Meteorol. 11 89-102 